\title{
Enhancement of Electrical Energy Transaction through the Development of a Prepaid Energy Meter using Gsm Technology
}

\author{
J. Tsado ${ }^{1}$, B. M Mustapha ${ }^{2}$, Abubakar Isah Ndakara ${ }^{3}$ \\ ${ }^{1,3}$ Department of Electrical/Electronic Engineering, Federal University of Technology Minna, Niger State, \\ Nigeria \\ ${ }^{2}$ Department of Electrical \& Electronics Engineering University of Maiduguri, Nigeria
}

*Corresponding Author: Abubakar Isah Ndakara, Department of Electrical/Electronic Engineering, Federal University of Technology Minna, Niger State, Nigeria

\begin{abstract}
This paper presents the development of a prepaid energy meter using GSM technology to enhance electrical energy management. The objectives are to develop an energy meter with mobile payment option, mitigation of electricity theft, and reduction of billing errors as compared to the previous energy meters. The metering system consists of voltage and current sensors. The monitoring and control system consists of GSM module, real time clock, relay and an ATMEGA328 microcontroller programmed in C-Language. The meter is designed to have a peak and off peak period with corresponding meter billings for both periods. It also carries out the following instructions: it automatically sends an SMS informing the consumer whose phone contact have been programmed into the system about his/her units at preset times; whenever the energy units is below a certain value or if a payment has been made, an SMS is sent to the consumer; it also disconnect and connect supply respectively through a connected relay. The results obtained shows that the system responded as programmed: the subscriber's phone number and the meter were registered successfully, the meter was recharged and also a message was sent to the subscriber about his/her recharge status from the service provider, by this, the subscriber would have less contact with the meter and the issue of electricity theft through meter by-pass would be reduced along with the time wasted by consumers to line up for the purchase of energy unit.
\end{abstract}

Keywords: ATMEGA328, Current sensor,GSM module, Relay, Real time clock and Voltage sensor.

\section{INTRODUCTION}

Efficient usage of electricity has become an important concern worldwide. This has urged utilities throughout the world to shift from conventional electromechanical meters to smart meters which provide better security and control [1]. A Prepaid Energy Meter enables power utilities to collect electricity bills from the consumers prior to its consumption. The prepaid meter is not only limited to Automated Meter Reading [AMR] but is also attributed with prepaid recharging ability and information exchange with the utilities pertaining to customer's consumption details. The idea of prepaid metering is very important for the new fields of Micro-grid and Smart Grid and is an inevitable step in making any grid smarter than it is now [2].Electricity theft is not a new phenomenon but it is becoming important because of its impact on the cost of electricity to consumers and the utility companies particularly in developing countries like Nigeria [4]. Unlike other forms of theft, electricity theft hardly carries strict penalties. Recently, there has been the development of more stringent measure to deal with those who take part in the fraudulent extraction of electricity in Nigeria. There are four main ways that electricity can be accessed illegally [3]. Electricity can be fraudulently accessed through illegal hook-ups, meter tampering or bypass, billing irregularities and unpaid bills [5]. Illegal hook-ups occur when electrical wires are directly connected to the grid system from the individual's premises. High risks of electrocution and electrical fires are associated with this type of electricity theft. Meter related theft is found among major households because it is technically easier and usually requires little or no electrical wiring knowledge [6]. Meter tampering can be done by inserting a device into the meter resulting in an inaccurately lower reading on the meter. This tampering can be detected only by an audit on the premises or by discrepancies in the electricity bill. Meter bypass occurs when some of the wiring of the premises is engineered to not pass through the 
meter. Like meter tampering, this is also very difficult to detect. Billing irregularities is a manifestation of corruption in the utility company through bribes to utility officials. Usually, the meter reader is compensated for not reporting the accurate electricity usage of the property. Refusal to pay electricity bills is a common practice by all socioeconomic groups [7]. The utility company has the greatest control over this since they are able to disconnect customers for unpaid bills. Disconnections are usually a prelude to another form of electricity fraud. Power theft is a serious problem and when not checked and prevented can derail the growth and progress of an economy [8].In this research work, a prepaid energy meter using GSM technology to enhance electrical energy management was designed and implemented to provide a high level of energy management through an advance algorithm embedded in a microcontroller to monitor peak and off- peak periods with subsequent energy consumption rate; that is, for the peak period the energy is recorded as it is being consumed while for the off-peak period the energy recorded is $80 \%$ the energy consumed. This enables the consumer to manage his/her energy consumption rate at a reduced cost. The energy meter was also designed to communicate to the consumer through a GSM module by sending a message to the consumer's registered phone number which was programmed in the microcontroller, with information about recharge made to the service provider. It also informs the consumer when the preset threshold is reached. If the value of energy gets to $50 \mathrm{WHr}$ a message is sent to the consumer to make a recharge; a relay connected to the meter disconnects the consumer from the energy supply when the unit get to zero and recharge is not made. This minimizes the problem of electricity theft as the meter could be install outside the reach of consumer and helps improve energy management as consumers make a conscious effort to reduce energy wastage during peak and off-peak periods; consequently reducing the tariffs.

\section{Materials AND Methods}

The block diagram in Figure1 shows the monitoring, metering and control System of the design which is discussed below.

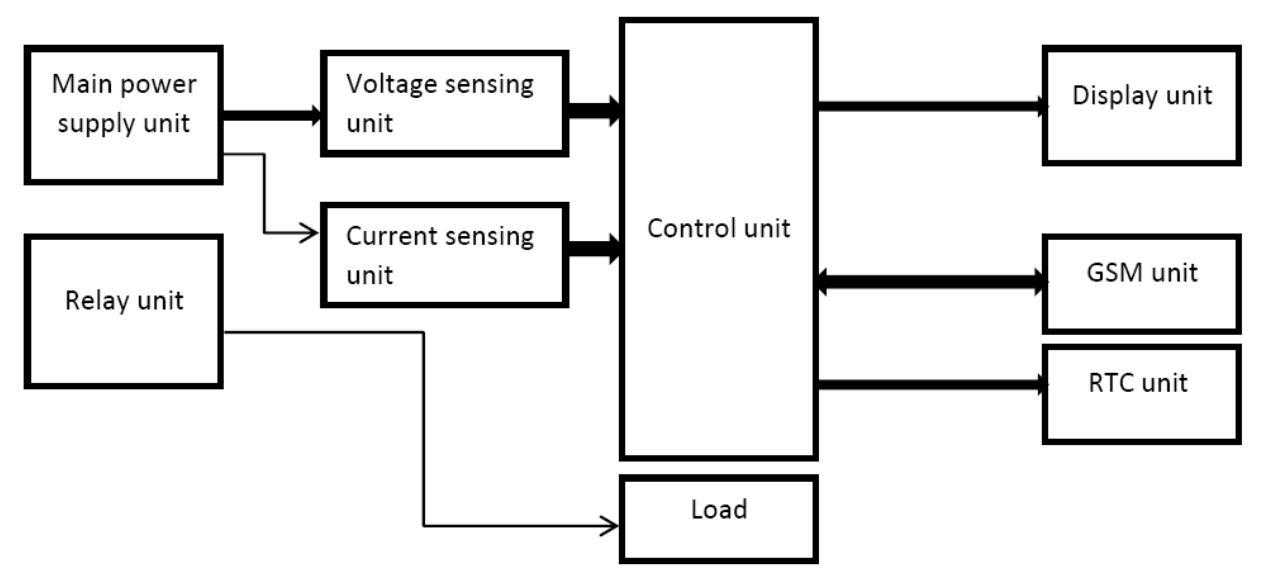

Figure1. Block Diagram of the Monitoring, Metering and Control System Design

\subsection{The Power Supply Unit Design}

The source of power is from AC mains. The AC power supply was transformed from $220 \mathrm{Vac}$ to $15 \mathrm{Vac}$. The transformed voltage was then rectified to DC using a bridge rectifier and filtered using a capacitor. The rectified dc was then regulated to $5 \mathrm{Vdc}$ using a $5 \mathrm{~V}$ regulator (LM7805) and $12 \mathrm{Vdc}$ using a $12 \mathrm{~V}$ regulator (LM7812).

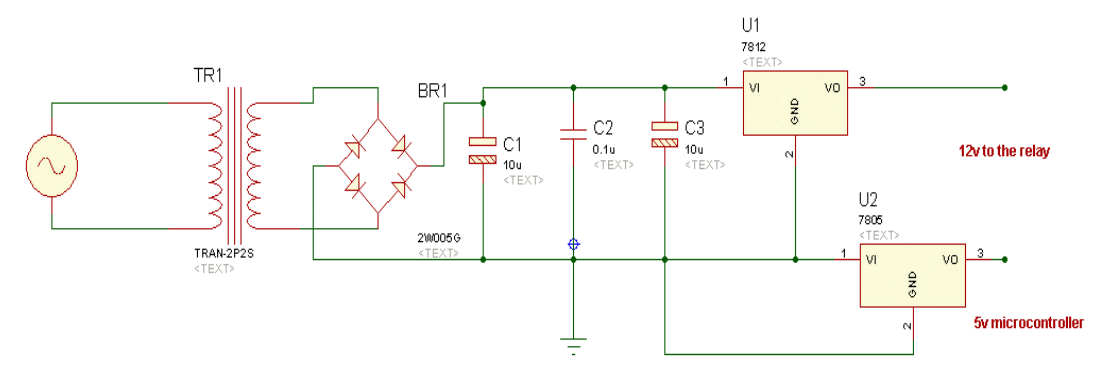

Figure2. The circuit diagram of the power supply 


\subsection{The Control Unit}

The control unit uses a microcontroller ATMEGA328 which has internal ADC and memory. The controller was clocked with a frequency of $16 \mathrm{MHz}$. This is used to achieve a compact system since two ADC is needed to check both the voltage and current. The controller is programmed to communicate with the LCD, GSM module and relay connected to the load which is responsible for the switching. The basic connection of the controller is shown in Figure3.

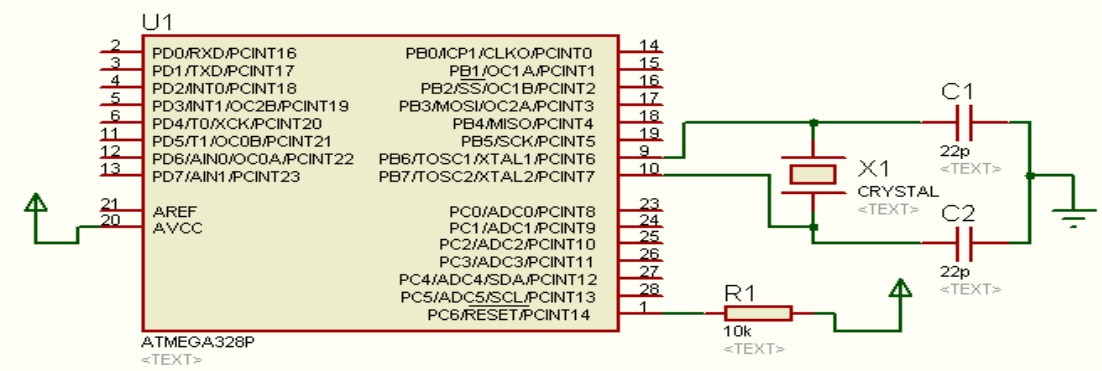

Figure3. Microcontroller Circuit Connection

Pin 7 which is the $\mathrm{V}_{\mathrm{cc}}$ is connected to $5 \mathrm{~V}$ as specified in the datasheet which is to power the controller while pin 8 is grounded.

\subsection{Display Unit}

This unit is achieved by the use of an LCD. The datasheet instruction is needed in interfacing the LCD with the controller. The different control signals that could initialize the system were specified. All these instructions were adhered to for success in the prototype made. The symbolic representation of the device is shown in Figure4.

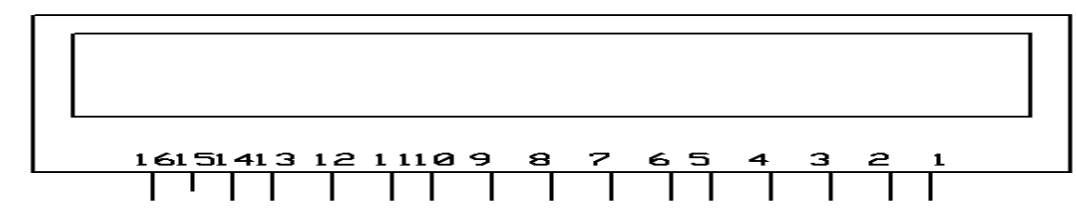

Figure4. Symbolic Representation of an LCD

\subsection{Relay Unit}

The unit aids in switching between the consumers supplies; that is, when a recharge has been made and vice versa. The diagram in Figure 5 is the relay circuit.

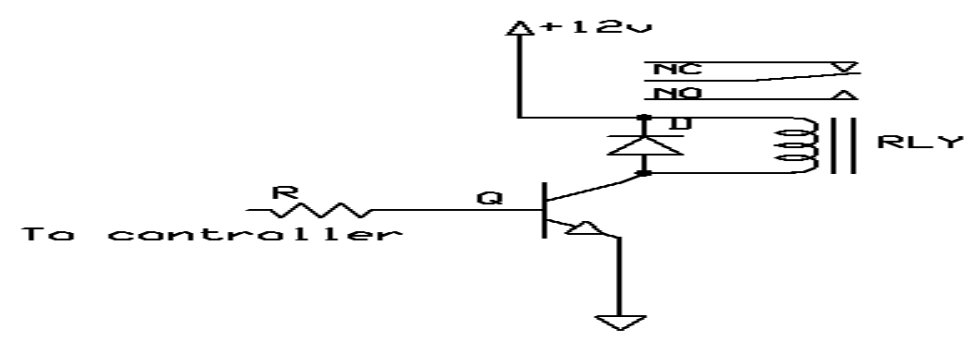

Figure5. Relay Circuit

\subsection{Current Sensing Unit}

A filament bulb rated 60 watts was connected to a supply of $220 \mathrm{Vac}$. Therefore the total current flowing through the load will be:

$\mathrm{I}=\frac{P}{\mathrm{~V} \cos \varnothing}$ 
Where $\mathrm{P}$ is the total power, I is the current, $\operatorname{COS} \emptyset$ is the power factor and $\mathrm{V}$ is the voltage also 0.8 was chosen as the power factor for maximum efficiency.Figure6 shows the circuit diagram of the current sensing unit.

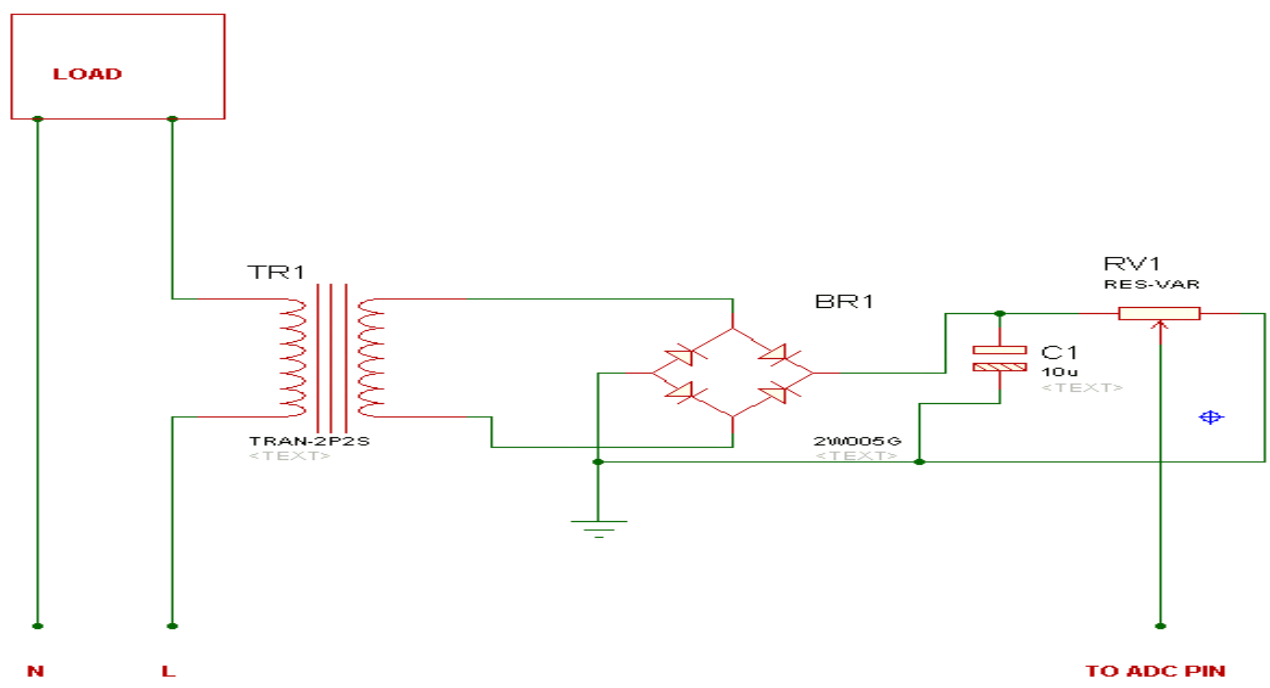

Figure6. Circuit of the Current Sensing Unit

\subsection{Voltage Sensing Unit}

The unit was achieved via the use of a step down transformer rated $220 / 15 \mathrm{~V}$. The voltage rating of the transformer was then scale down to 1:100 with the help of variable resistor such that when the input voltage was $220 \mathrm{~V}$ the voltage at the output of the variable resistor that goes to the microcontroller was $2.2 \mathrm{~V}$. Figure7 shows the circuit diagram of the voltage sensing unit.

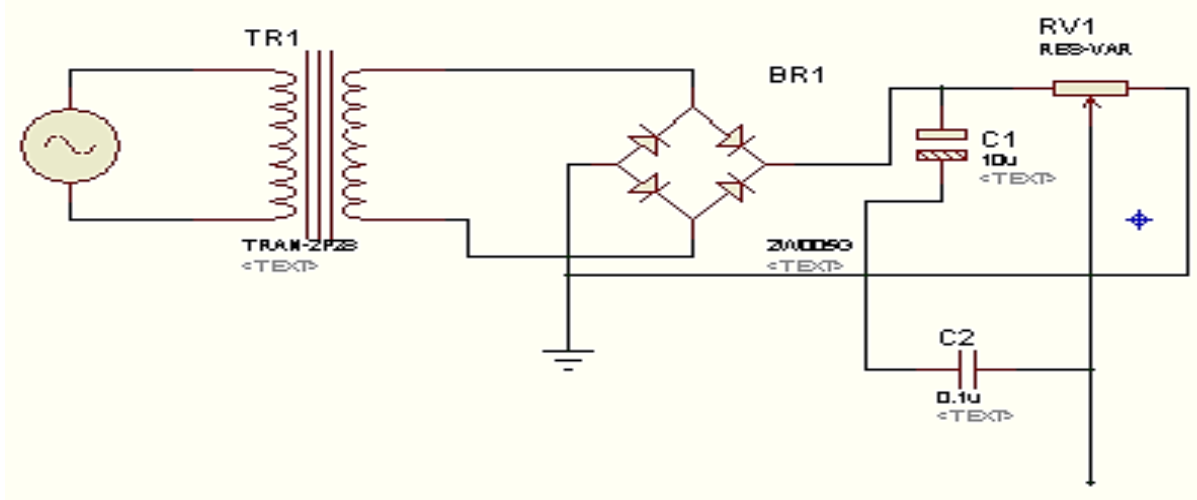

TOADC PIN

Figure7. Circuit of the Voltage Sensing Unit

\subsection{Real Time Clock Unit}

This unit was used to keep the present time and date in the sense that the peak and off peak period depends on time.

\subsection{GSM Module Unit}

The GSM module used is SIM900. It was set to the baud rate of $9600 \mathrm{bits} / \mathrm{sec}$ so it can communicate with the controller. The type of serial communication used is USART (Universal Synchronous Asynchronous Transmission) and this component is controlled using AT (Attention) commands.

\section{OVerall Circuit Diagram OF The System}

The overall circuit diagram comprises the metering, monitoring and control unit. This is shown in Figure8. 
Enhancement of Electrical Energy Transaction through the Development of a Prepaid Energy Meter using Gsm Technology

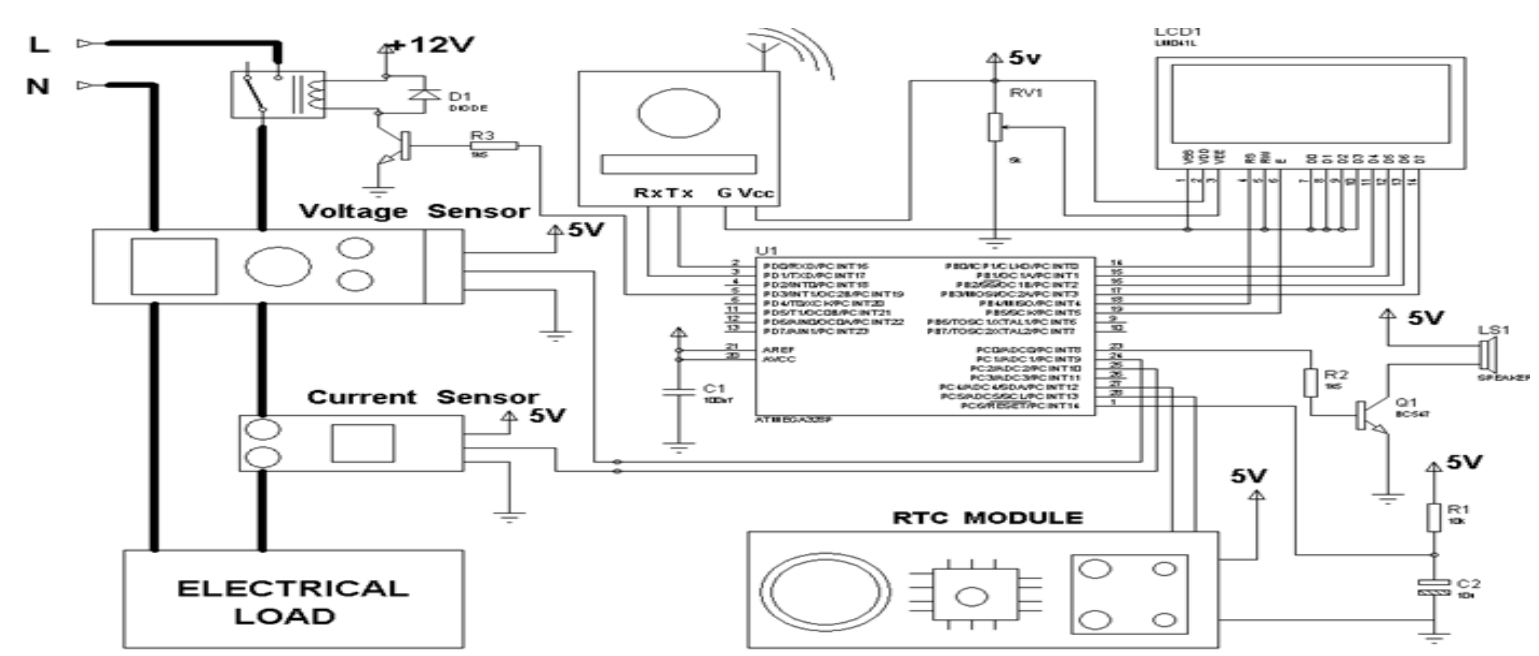

Figure8. Circuit diagram of the Overall Design

\subsection{Construction of the Prepaid Energy Meter Casing}

The prepaid energy meter casing was locally constructed using plastic in four corners to form a box. The casing constructed is shown in Plate1.

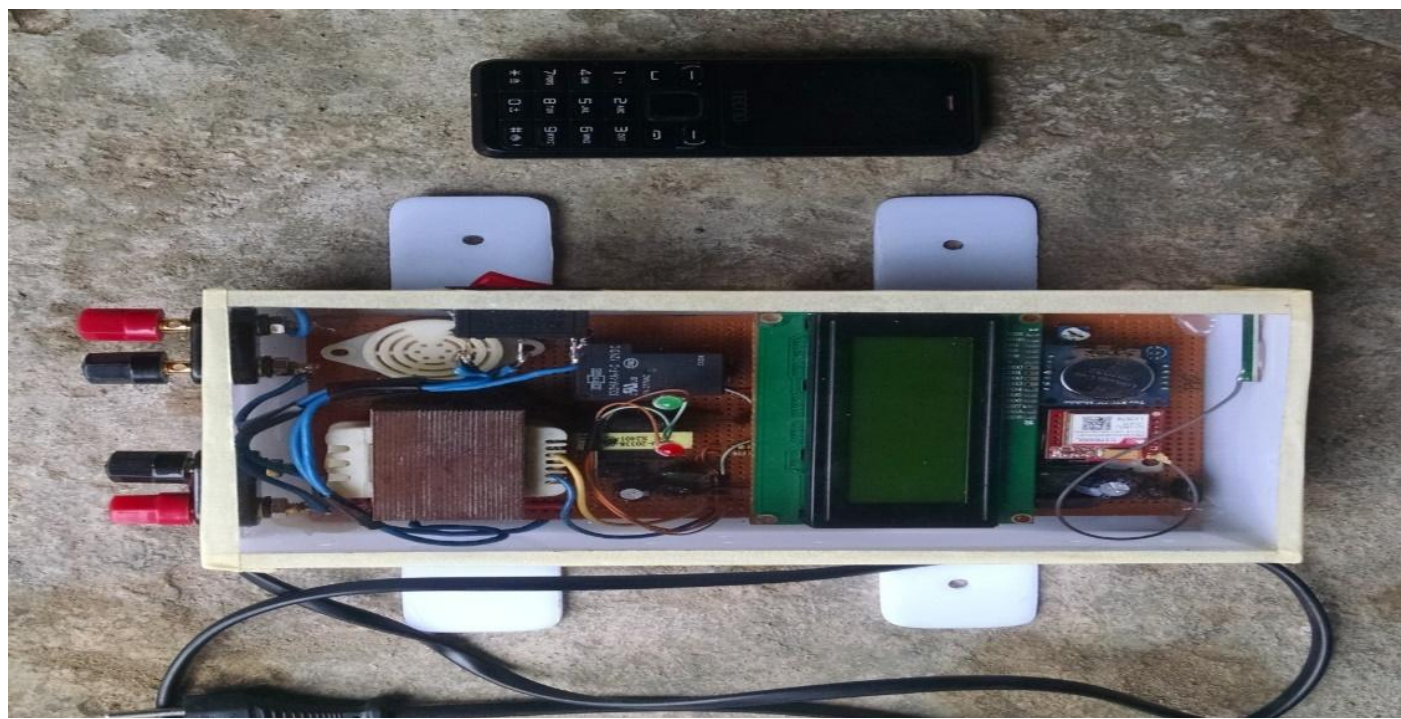

Plate1. Casing of the prepaid energy meter

\section{TEST AND RESUlTS}

The testing of components of the prototype system was carried out before the implementation was made. A multi-meter was used to measure the voltage and current output of the voltage and current sensors. The measured values were recorded. The electronic components used for the monitoring and control circuit was initially tested on a bread board before it was finally soldered to a Vero board.

Table1 shows the communication between the monitoring and control unit when all units are connected. The prototype of the monitoring and control unit is shown in Plate2. The system responded as programmed. A response for status inquiry, unit availability and switching of relay was all tested. The messages displayed on the LCD and phone is shown in Plate3.

Table1. Communication of the monitoring and control circuit

\begin{tabular}{|l|l|l|}
\hline Function & Message Sent & Response Received \\
\hline $\begin{array}{l}\text { To store the number of the } \\
\text { subscriber or consumer }\end{array}$ & $\begin{array}{l}\text { A message with the caption; \#I AM } \\
\text { THE USER: 07030542277. was } \\
\text { sent }\end{array}$ & $\begin{array}{l}\text { Subscriber's number saved } \\
\text { successfully. }\end{array}$ \\
\hline To recharge energy meter & $\begin{array}{l}\text { A message with the caption; } \\
\text { \#RECHARGE: 100. was sent }\end{array}$ & $\begin{array}{l}\text { Meter was recharged with 100WHr } \\
\text { successfully. }\end{array}$ \\
\hline
\end{tabular}




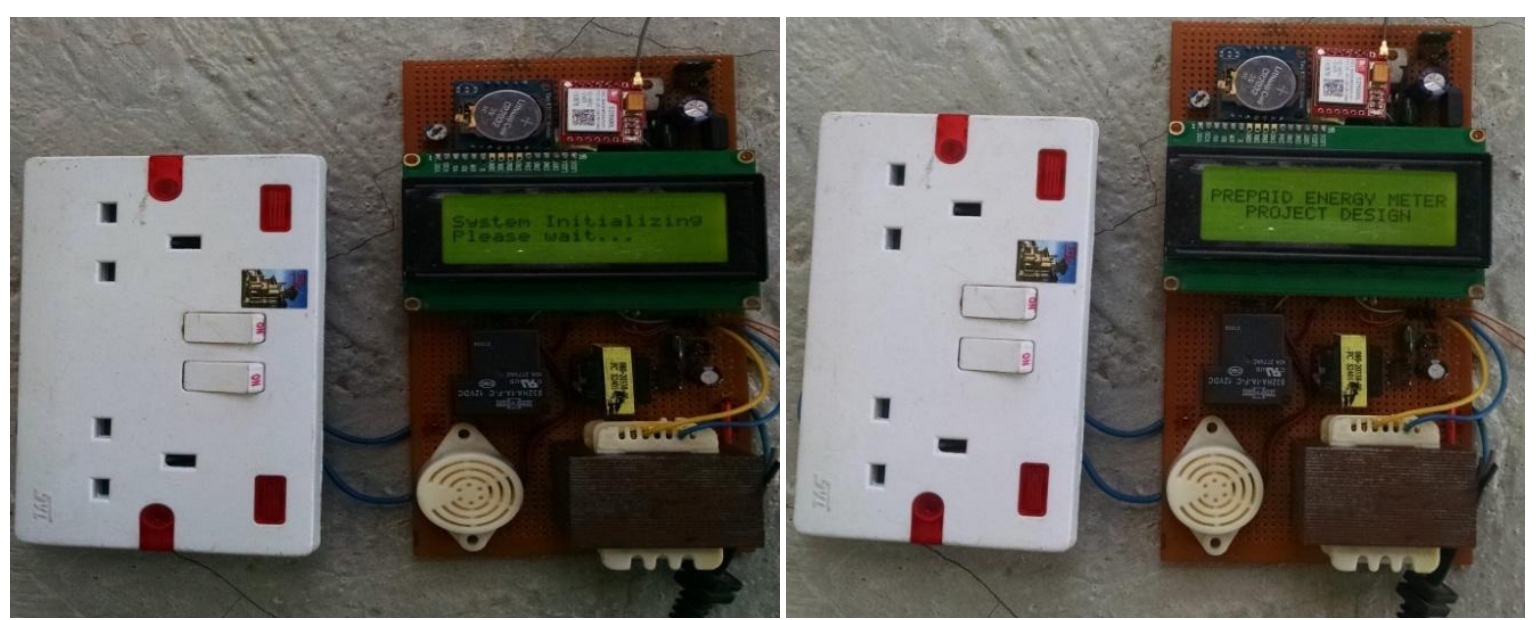

Plate2. Picture Display of the Monitoring and Control System

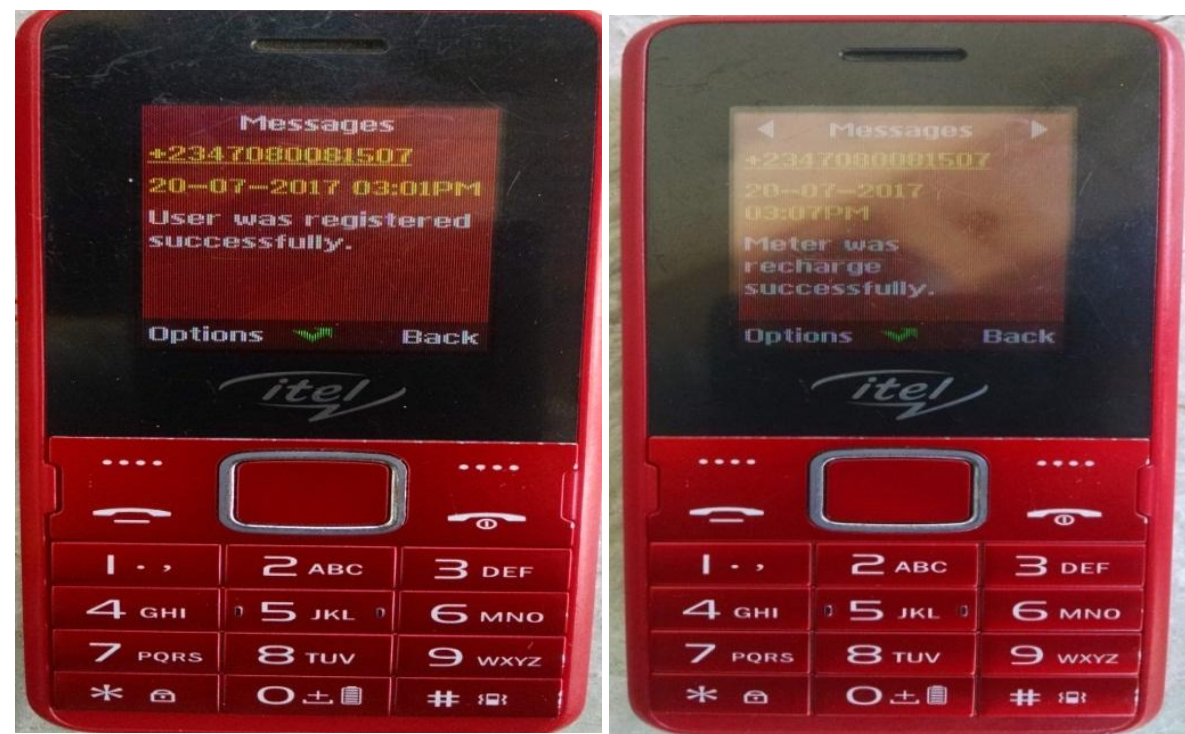

Plate3. Pictures of Messages Displayed on Phone

\subsection{Discussion of Result}

The LCD in the circuit of the monitoring and control displays every action taken and message received by the microcontroller.

When the energy level of the energy meter gets to a preset threshold, a message is automatically sent only to the GSM number that was included in the programming of the microcontroller. Figure9, 10, 11 and 12 shows all the actions on the LCD as simulated using Proteus ISIS.

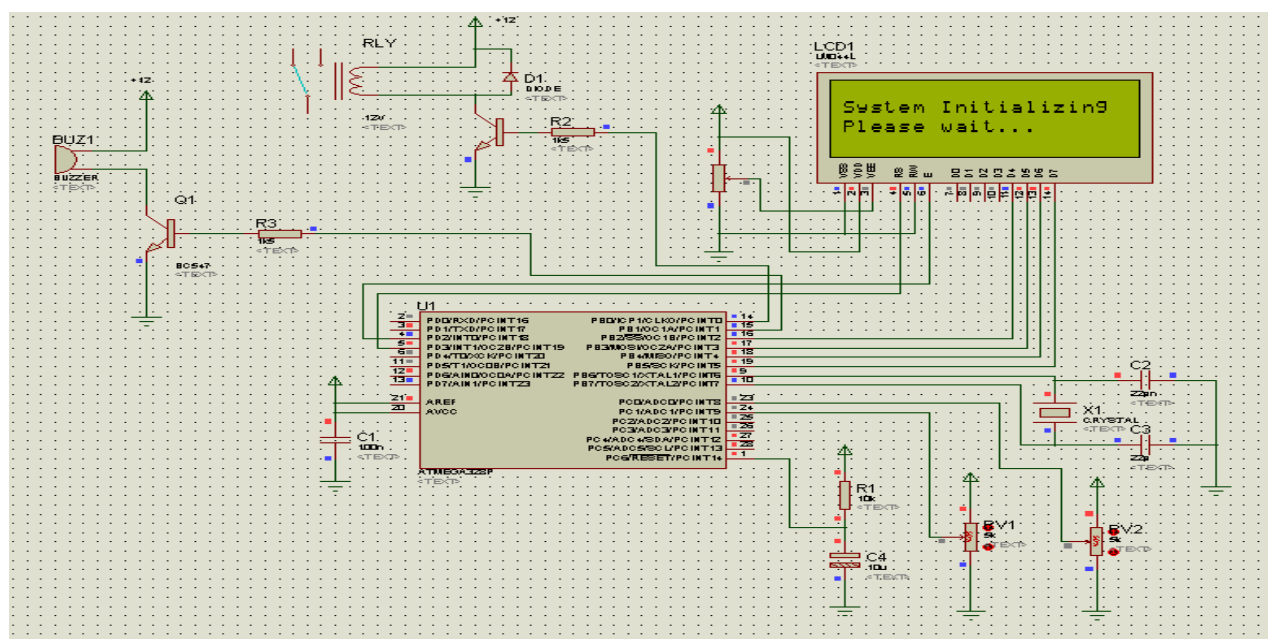

Figure9. Result on initializing display on the $L C D$ 
Enhancement of Electrical Energy Transaction through the Development of a Prepaid Energy Meter using Gsm Technology

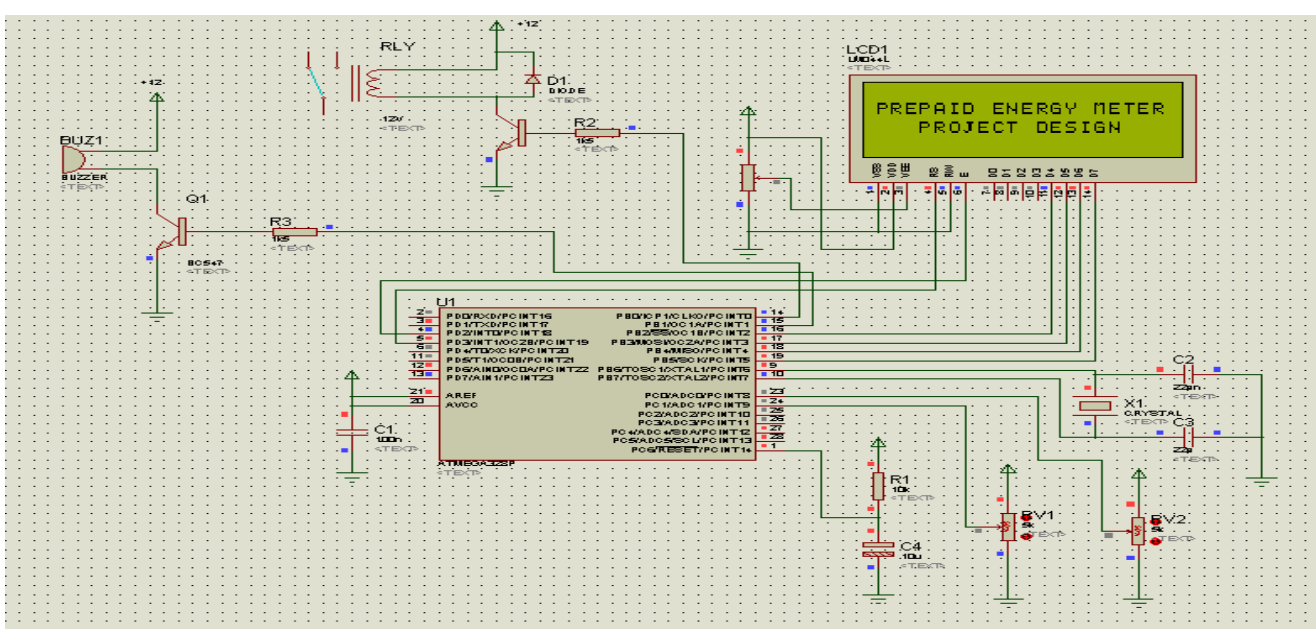

Figure10. Result on LCD of the prepaid energy meter

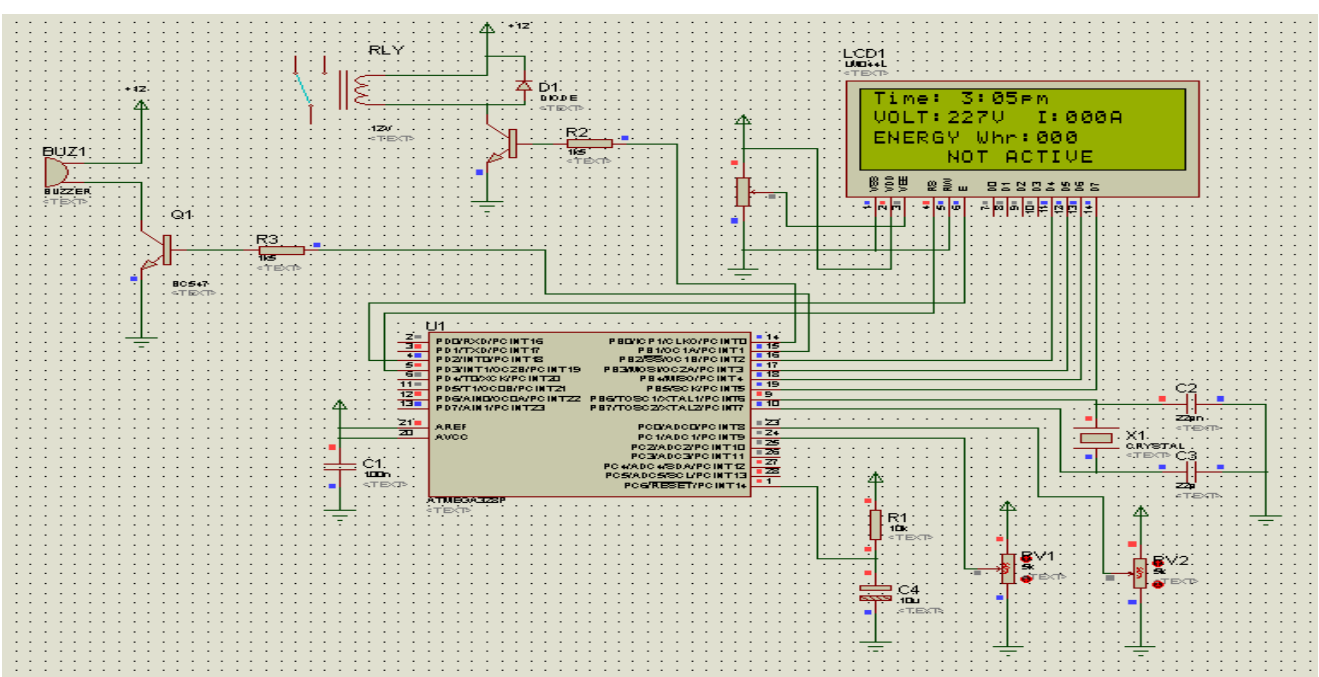

Figure11. Result on LCD when the energy meter is not active

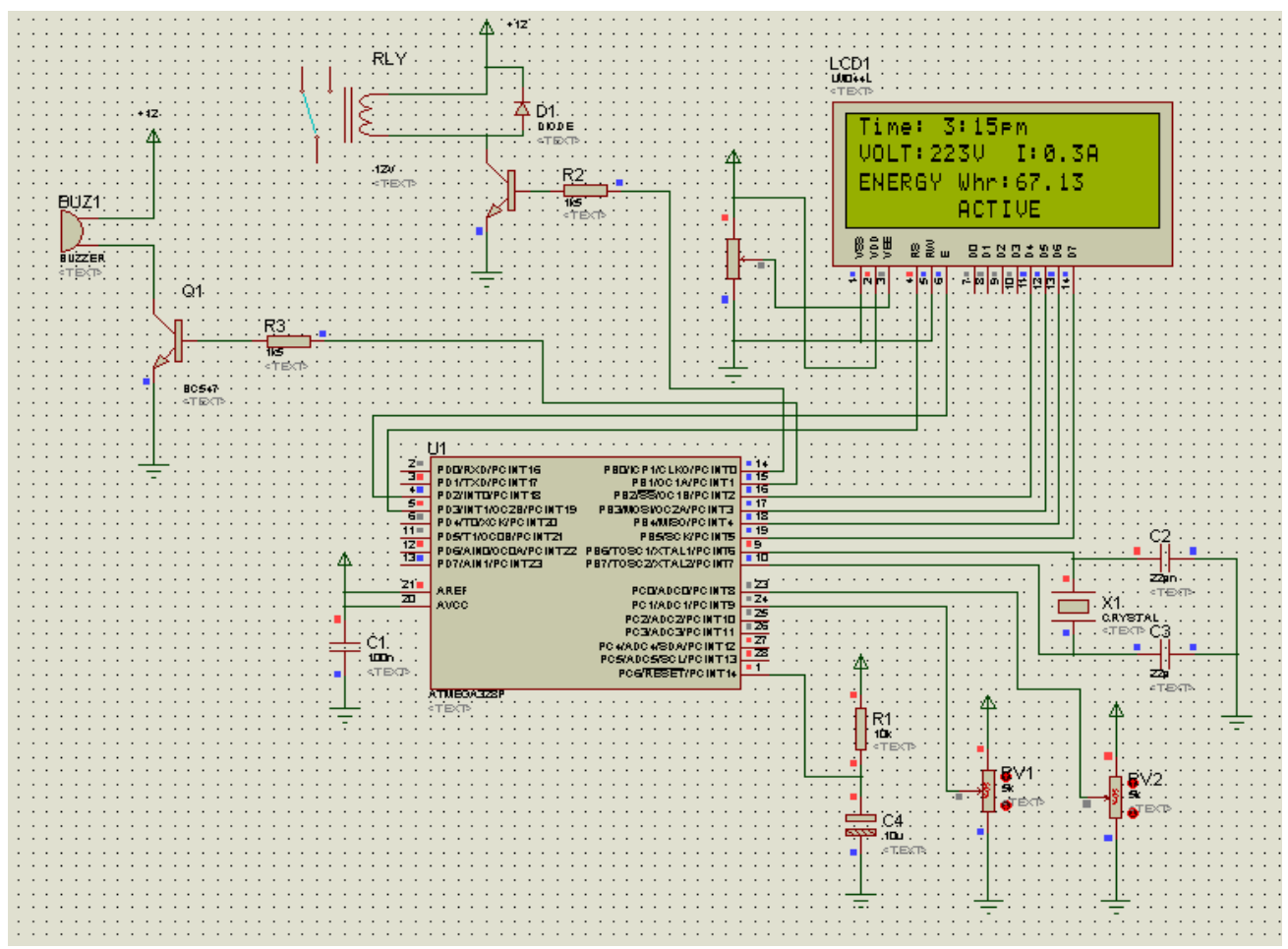

Figure12. Result on LCD when the energy meter is active 


\section{CONCLUSION}

The following conclusions are drawn from this research work; the integration of peak and off peak period match was able to enhance better energy management, an alternative means of monitoring and control of the energy meter created a better means of widening the communication of the status of the meter through text messages thereby reducing the usual regular physical inspection by utility staff also the introduction of GSM technology into the meter provided an easy way of recharging.

\section{REFERENCES}

[1] Anas, N., Javaid, A., Mahmood, S., Raza, U., \& Khan, Z. (2012). Minimizing Electricity theft.Seventh InternationalConference on P2P, Parallel, Grid, Cloud and Internet computing and Communication Engineering, 3, 17-23.

[2] Amit, J., \& Mohnish, B. (2011).A prepaid meter using mobile communication. International Journal of Engineering, Science and Technology, 3, 160-166.

[3] More, D., Vijay, A., Pravin, M., \&Avinash, S. (2016). GSM based power theft monitoring at local distribution system with prepaid energy meter. Global journal of engineering science and researches, 3 , 24-28.

[4] Dike, O.,Uchechukwu, A., Euphemia, C., \& Blessing C. (2015). Minimizing Household Electricity Theft in Nigeria Using GSM Based Prepaid Meter. American Journal of Engineering Research, 4, 59-69.

[5] Fawzi, A., \& Bahaa, J., (2011). Building a Prototype Prepaid Electricity Metering System Based on RFID.International Journal of Electronics and Electrical Engineering, 1, 20-36.

[6] Jaychand, U., Namita D., Alrina D., \& Glenie F. (2015). Prepaid Energy Meter with GSM Technology. International Journal of Innovative Research in Computer, 3, 2048-2054.

[7] Rodrigo, W., Lakmal, H., Roshani, N., Samarakoon, S., \& Samararatne, S. (2016). Prepaid Energy Meter Using GPRS Technology for Improved Metering and Billing. International Journal of Computer Science and Electronics Engineering, 4, 64-69.

[8] Srikanth, G., \& Yousuf, M. (2015).Implementation of GSM Based Prepaid Remote Energy Meter and Billing System.International Journal of Scientific Engineering and Technology Research, 2, 40-56.

\section{AUTHORS' BIOGRAPHY}

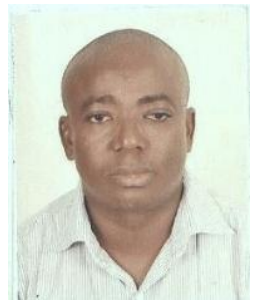

J. Tsado, obtained his Bachelor of Engineering Degree (B. Eng.) in Electrical \& Computer Engineering from Federal University of Technology Minna, Nigeria in 1998. He also obtained M. Eng and Ph.D in Electrical Power System \& Machine from University of Benin, Benin city,Nigeria in 2001 and 2007 respectively.

He is an Associate Professor and the current Head of Department for Electrical and Electronics Engineering, Federal University of Technology Minna, Nigeria, since December 2016. He was the Industrial liaising officer of Federal University of Technology, Minna between 2009 to 2011 and was the Head of Department Computer Engineering at Federal University of Technology, Minna between 2011 and 2012. He has authored and co-authored quite number of published journal papers and conference proceeding. His research area is power system and energy studies with special interest in Protection Schemes.

Engr. Dr. Tsado was a member of IEEE, Nigerian Society of Engineers (NSE) and a Council for the Regulation of Engineering in Nigeria (COREN) registered engineer. He is also an editorial member of the Engineering Journal of the Federal University of Technology, Minna. He recently received an award for excellence from Nigerian Society of Engineers (NSE) Minna Branch, in her quarterly public lecture held at Shiroro Hydro Generation Station, Niger State.

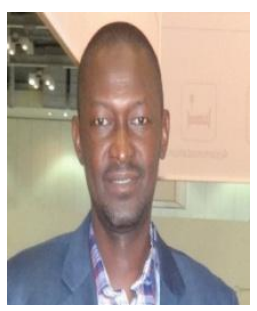

B. M. Mustapha, was born in Maiduguri, Borno State, Nigeria. He received his Bachelor of Engineering degree in Electrical \& Electronics from university of Maiduguri, Borno State Nigeria in 1992 and Master of Engineering degree from Bayero University Kano, Nigeria in 1998. He obtained his Doctor of philosophy $(\mathrm{Ph}$. D) from Abubakar Tafawa Balewa University Bauchi, Nigeria in Control Engineering in 2010. He has been a lecturer with University of Maiduguri from 1994 to date. He has participated in a number of national and international meetings, conferences, seminars and workshops in Engineering and Spectrum Management. 

using Gsm Technology

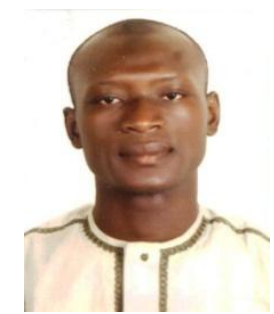

Abubakar Isah Ndakara, is a Teacher. He is a native of Muwo, Mokwa Local Government Area of Niger State. He attended Government Secondary School Minna, where he obtained his Senior Secondary School Certificate in 2007. He got his Bachelor of Engineering (B.Eng.) degree in Electrical and Computer Engineering from Federal University of Technology Minna, Nigeria in 2012. During his service year as a youth corp member (N.Y.S.C) he lectured at the department of Electrical/Electronic Engineering, Sokoto State Polytechnic in the year 2013. Currently, he is a Master's degree (M.Eng.) student in Electrical Power and Machines, Federal University of Technology MInna, Nigeria. His research interest includes C-Language programming and Electronics.

Citation: Abubakar Isah Ndakara et al.(2017). Enhancement of Electrical Energy Transaction through the Development of a Prepaid Energy Meter using Gsm Technology, International Journal of Research Studies in Electrical and Electronics Engineering (IJRSEEE), 3(4), pp.10-18, DOI: http://dx.doi.org/10.20431/24549436.0304003.

Copyright: () 2017 Abubakar Isah Ndakara et al. This is an open-access article distributed under the terms of the Creative Commons Attribution License, which permits unrestricted use, distribution, and reproduction in any medium, provided the original author and source are credited 